\title{
Pengelolaan Supervisi Akademik Sekolah Dasar Islam Terpadu Ash-Haabul Kahfi Lubuk Alung
}

\author{
Asnita Putri Dewi \\ Pasca Sarjana Universitas Negeri Padang \\ asnitaputri5@gmail.com
}

\begin{abstract}
This study aims to determine how the management of academic supervision at the Ash-Haabul Kahfi Lubuk Alung Integrated Islamic Elementary School in improving teachers competency and professionalism. The research approach was conducted qualitatively with descriptive methods. Data collected through observation, interviews, and documentation. The results of the study are: (1) In conducting academic supervision planning activities, the school principal had implemented it well. The school principal and teachers had compiled a one-year program design through the school meeting forum. (2) In the process of conducting academic supervision, the principal is considered to have no understanding of academic supervision, because it only focuses on teacher administration examination only (3) Follow-up academic supervision has not been maximized run by the principal as a supervisor, because only fostering teachers whose administration are incomplete. The lack of guidance for school principals related to the learning process, teacher skills in teaching, makes teachers not experience a significant increase in terms of competence and profession as a teacher.
\end{abstract}

Keywords: Management, Academic Supervision, SDIT Ash-Haabul Kahfi

\section{Article Info}

\section{PENDAHULUAN}

Penelitian ini diawali dengan temuan dari peneliti pada tanggal 2 September 2019, bahwa kinerja guru Sekolah Dasar Islam Terpadu Ash-Haabul Kahfi belum berjalan sebagaimana mestinya. Terbukti sebagian besar guru yang kurang disiplin terkait jam kedatangan, persiapan administrasi pembelajaran, kurangnya pengalaman dalam mengajar, bahkan ada guru yang asyik berbicara dan melakukan pembiaran siswa untuk keluar masuk kelas tanpa terkontrol pada saat jam pelajaran berlangsung. Hal ini tentu saja tidak bisa dibiarkan begitu saja. Karena ini bisa merusak kinerja guru yang akan berimbas pada kualitas sekolah juga kedepannya.
Hasil wawancara awal peneliti dengan Ibu Hj. Dra. Huriah selaku kepala sekolah di Sekolah Dasar Islam Terpadu Ash-Haabul Kahfi pada tanggal 3 September 2019, bahwa kualitas mengajar guru masih rendah. Salah satu faktor penyebabnya adalah banyaknya guru yang kurang berpengalaman dan berasal dari bidang keilmuan yang tidak sesuai dengan pengajaran sekolah dasar. Selain itu kontrol dari kepala sekolah pun masih kurang maksimal mengingat banyaknya agenda kegiatan dinas luar sehingga jalannya supervisi kurang maksimal. Hal ini sesuai dengan (Supardi, 2014) bahwa tinggi rendahnya motivasi dan prestasi guru tidak terlepas dari rendahnya 
kontribusi kepala sekolah dalam melakukan pembinaan pada kegiatan supervisi.

Mengingat pentingnya peranan guru dalam mencapai kesuksesan belajar pada siswa, maka guru haruslah mempersiapkan segala sesuatunya dengan maksimal agar siswa bisa belajar dengan efektif sesuai dengan tahapan perkembangannya. Mengacu pada Permendiknas Nomor 41 tahun 2007 tentang Standar Proses, guru pada satuan pendidikan wajib menyusun RPP dengan lengkap dan sistematis sehingga guru dapat melaksanakan kegiatan pembelajaran secara aktif, kreatif, efektif dan menyenangkan (PAKEM). Pembelajaran yang didesain dengan menarik akan mampu menciptakan pembelajaran efektif yang tentunya disukai oleh semua siswa. Dengan demikian, dapat dipastikan tujuan pembelajaran akan mudah dipahami dan dicapai oleh siswa.

Untuk melihat dan menilai serta membantu kinerja guru agar semua kegiatan yang telah terprogram dapat berjalan secara efektif dan efisien serta sesuai dengan apa yang telah direncanakan diperlukan pengawasan atau supervisi oleh kepala sekolah. Kepala sekolah sebagai supervisor sangatlah berperan penting dalam menggerakkan dan mendorong profesionalitas guru. Karena salah satu kompetensi yang harus dimiliki oleh kepala sekolah adalah supervisi. Hal ini sesuai dengan Permendiknas Nomor 13 Tahun 2007 yang menyatakan bahwa kompetensi yang harus dimiliki oleh kepala sekolah/madrasah ada 5, diantaranya (1) kompetensi manajerial (2) kompetensi kewirausahaan (3) kompetensi supervisi (4) kompetensi kepribadian dan (5) kompetensi sosial. Sebesar apapun masalah pendidikan yang dihadapi guru dan sekolah akan mudah untuk diatasi, jika keduanya memiliki pemahaman terhadap supevisi akademik. Karena keberhasilan kerjasama antar keduanya merupakan gambaran dari keberhasilan kualitas sekolah.
(Rifma, 2016) mengatakan bahwa supervisi merupakan semua usaha atau serangkaian kegiatan yang dilakukan supervisor atau pembina untuk membantu guru dalam meningkatkan kualitas pembelajaran agar efektif dan efisien. (Sahertian, 2010) dan (Kristiawan, Yuniarsih, \& Fitria, 2019) juga mengatakan bahwa supervisi adalah usaha memberi layanan kepada guru-guru baik secara individual maupun secara kelompok dalam usaha memperbaiki pengajaran.

Sejalan dengan pendapat diatas, Permendiknas no. 39 tahun 2009 menyebutkan bahwa ruang lingkup supervisi akademik meliputi: a) membina guru dalam merencanakan, melaksanakan dan menilaia proses pembelajaran, b) memantau pelaksanaan standar isi, c) memantau pelaksanaan standar proses, d)memantau pelaksanaan standar kompetensi kelulusan, e) memantau pelaksanaan standar tenaga pendidik dan f) memantau pelaksanaan standar penilaian.

Berdasarkan uraian masalah di atas, maka peneliti mengambil fokus masalah pada "Pengelolaan Supervisi Akademik Sekolah Dasar Islam Terpadu Ash-Haabul Kahfi Lubuk Alung?". Pertanyaan penelitian yang muncul untuk mengurai fokus masalah adalah: (1) Bagaimana Perencanaan supervisi akademik Sekolah Dasar Islam Terpadu Ash-Haabul Kahfi Lubuk Alung? (2) Bagaimana Pelaksanaan supervisi akademik Sekolah Dasar Islam Terpadu Ash-Haabul Kahfi Lubuk Alung? (3) Bagaimana tindak lanjut supervisi akademik Sekolah Dasar Islam Terpadu AshHaabul Kahfi Lubuk Alung?

Tujuan dari penelitian ini adalah untuk mendeskripsikan pengelolaan supervisi akademik Sekolah Dasar Islam Terpadu AshHaabul Kahfi Lubuk Alung melalui uraian berikut: (1) Untuk mengetahui perencanaan supervisi akademik Sekolah Dasar Islam Terpadu Ash-Haabul Kahfi Lubuk Alung. (2) Untuk mengetahui elaksanaan supervisi akademik Sekolah Dasar Islam Terpadu Ash- 
Haabul Kahfi Lubuk Alung. (3) Untuk mengetahui tindak lanjut supervisi akademik Sekolah Dasar Islam Terpadu Ash-Haabul Kahfi Lubuk Alung

Hasil penelitian ini diharapkan dapat dijadikan sebagai salah satu bahan kajian dalam memberikan informasi dan pengetahuan kepada peneliti lainnya, sehingga penelitina ini dapat menjadi bahan literatur bagi pembaca.

Hasil penelitian ini akan dijadikan sebagai salah satu alternatif atau solusi pelaksanaan sistem pendidikan saat ini terhadap kulitas sekolah, dan diharapkan sebagai bahan informasi dan evaluasi bagi segenap keluarga besar Sekolah Islam Terpadu Ash-Haabul Kahfi agar memperbaiki dan meningkatkan kualitas mutu pendidikan demi kemajuan sekolah tersebut

\section{KAJIAN PUSTAKA}

Menurut (Hersey, Blanchard, \& Johnson, 2008) pengelolaan merupakan proses bekerjasama secara individu dan kelompok serta sumber daya lainnya untuk mencapai tujuan organisasi. Hal ini juga sejalan denga pendapat (Hasibuan., 2005) yang mengatakan bahwa manajemen adalah ilmu dan seni mengatur proses dan mengefektifkan sumber daya manusia dan sumber daya lainnya guna mencapai tujuan organisasi.

Luther Gulick dalam (Handoko T. Hani, 2011) mengatakan bahwa Manajemen sering diartikan sebagai ilmu, kiat dan profesi. Hal ini karena manajemen dipandang sebagai suatu bidang pengetahuan yang secara sistematik yang berupaya memberikan pemahaman mengenai apa dan bagaimana manusia bisa bekerjasama guna menggapai keberhasilan yang bisa bermanfaat bagi kemanusiaan.

Di sisi lain, (Follet, 2007) juga berpendapat bahwa manajemen merupakan sebuah seni untuk melaksanakan pekerjaan melalui orang lain. Menurut (Adisasmita, 2011), istilah pengelolaan sama dengan manajemen yaitu menggerakan, mengorganisasikan, dan mengarahkan usaha manusia untuk memanfaatkan secara efektif material dan fasilitas untuk mencapai suau tujuan.

Dari beberapa pengertian di atas, dapat disimpulkan bahwa pengelolaan adalah usaha dan seni mengatur pekerjaan dengan melibatkan orang lain untuk mau melaksanakan berbagai tugas untuk mencapai tujuan organisasi secara efektif.

Menurut (Snae, Budiati, \& Kumalayanti, 2017) Supervisi akademik adalah rangkaian kegiatan perencanaan, pelaksanaan, dan penilaian pembelajaran yang dilaksanakan di kelas secara baik dalam rangka peningkatan kompetensi guru dan merupakan tugas utama kepala sekolah untuk mengawasinya. Kepala sekolah dapat mengawasi jalannya proses pembelajaran yang dilaksanakan oleh guru dan membantu guru dalam meningkatkan kualitas pembelajaran melalui pelaksanaan supervisi akademik secara terprogram. Kualitas pembelajaran yang bermuara pada kualitas siswa, yakni siswa yang berakhlak mulia, berintegrasi, memiliki pengetahuan dan keterampilan yang memadai.

(Mulyasa, 2011) juga mengatakan bahwa supervisi akademik adalah bantuan profesional kepada guru, dengan siklus perencanaan yang tersistim dengan baik, kecermatan dalam mengamati dan umpan balik yang objektif dan segera. Bantuan yang diberikan kepada guru dalam meningkatkan kompetensinya dalam pengajaran dengan cara memberi masukan, arahan, pembinaan sesuai dengan perilaku guru dan penemuan solusi bersama sehingga kompetensi guru menjadi meningkat.

Senada dengan itu, (Sagala, 2010) menegaskan bahwa supervisi merupakan usaha yang dilakukan dalam rangka perbaikan proses belajar mengajar, meningkatkan kreativitas guru, memotivasi untuk melibatkan guru secara aktif dalam kegiatan sekolah yang pada akhirnya menimbulkan rasa memiliki terhadap 
sekolah dalam diri guru tersebut. Jika ini sudah terbentuk, maka guru akan memiliki rasa tanggung jawab dan memaksimalkan potensinya untuk mencapai tujuan sekolah.

Jadi, dapat disimpulkan bahwa supervisi akademik adalah segala usaha dan bantuan yang dilaksanakan oleh supervisor kepada guru dalam rangka meningkatkan kompetensi guru untuk mencapai pengajaran yang berkualitas.

Tujuan utama supervisi adalah untuk memperbaiki pengajaran dan meningkatkan kompetensi mengajar guru. Supervisor melaksanakan program supervisi untuk memotivasi guru agar mau berbuat menciptakan suasana belajar yang aktif dan kondusif dalam memaksimalkan potensi yang dimiliki peserta didik. Seorang supervisor dalam melaksanakan tugas professional yang dilakukan oleh kepala sekolah, penilik atau pengawas akan lebih berkualitas jika dilakukan berdasarkan prinsip supervisi (Daryanto \& Rachmawati, 2015)

Tujuan supervisi akademik adalah membantu guru-guru dalam

Mengembangkan proses belajar mengajar (2) Menerjemahkan kurikulum ke dalam bahasa belajar mengajar (3) Melihat tujuan pendidikan; membimbing pengalaman belajar mengajar, menggunakan sumber dan metode mengajar, memenuhi kebutuhan belajar dan mnilai kemajuan siswa, membina moral kerja,menyesuaikan diri,dan (4) Membantu mengembangkan profesional guru (5) Jadi, dapat disimpulkan bahwa tujuan dari supervisi akademik adalah memberikan layanan kepada guru secara profesional untuk memperbaiki pengajaran sesuai dengan kebutuhan guru guna meningkatkan kompetensi dan kualitas pembelajaran di kelas.

\section{METODE PENELITIAN}

Penelitian ini menggunaka penelitian deskriptif kualitatif, yaitu prosedur penelitian yang menghasilkan data berupa kata-kata tertulis atau lisan dari orang-orang dan pelaku yang diamati, diarahkan, pada latar belakang individu secara utuh (holistic) tanpa mengisolasikan individu dan organisasi dalam variable atau hipotesis, tetapi memandangnya sebagai bagian dari suatu keutuhan. Moleong (2010) menyatakan bahwa penelitian kualitatif adalah pengumpulan data dalam pengaturan alami, menggunakan metode alami, dan dilakukan oleh orang-orang atau peneliti yang secara alami tertarik.

Penelitian ini dilaksanakan di Sekolah Dasar Islam Terpadu Ash-Haabul Kahfi yang terletak di Jl. M. Yamin No.10 Teluk Belibi, Keamatan Lubuk Alung, Kabupaten Padang Pariaman, Sumatera Barat. Waktu pelaksanaan Mini Riset dilaksanakan sejak September 2019 hingga November 2019.

Data informasi diperoleh dari pengamatan secara langsung dan keterangan dari beberapa responden seperti Kepala Sekolah, guru dan karyawan SDIT Ash-Haabul Kahfi Lubuk Alung.

Teknik pengumpulan data dilakukan melalui wawancara yang mendalam terhadap informan, pengamatan di lapangan dan studi dokumen. Wawancara dilakukan dengan kepala sekolah, beberapa orang guru, dan karyawan di kantor. Observasi yang dilakukan adalah observasi terhadap subjek, perilaku subjek selama wawancara, interaksi subjek dengan peneliti dan hal-hal yang dianggap relevan sehingga dapat memberikan data tambahan terhadap hasil wawancara. Studi dokumen dengan melihatnya dalam bentuk dokumendokumen catatan, foto, buku, dokumen perencanaan supervisi akademik dari kepala sekolah, instrumen supervisi akademik, foto pelaksanaan kegiatan, catatan pelaksanaan supervisi akademik, dan dokumen tindak lanjut dari hasil supervisi,. Metode dokumentasi ini juga peneliti gunakan untuk mengumpulkan data dari sumber di lapangan seperti rekaman suara melalui handphone. Dokumen tersebut 
diharapkan akan membantu untuk mempertajam analisis mini riset ini.

Dalam penelitian ini, peneliti menggunakan teknik pemeriksaan keabsahan data melalui Triangulasi. Teknik triangulasi yang digunakan adalah teknik pemeriksaan yang memanfaatkan penggunaan sumber (wawancara dan triangulasi) dengan sumber berarti membandingkan dengan mengecek balik derajat kepercayaan suatu informasi yang diperoleh melalui waktu dan alat yang berbeda dalam metode kualitatif. Triangulasi ini dilakukan dengan cara :1)Membandingkan apa yang dikatakan orang di depan umum dengan apa yang dikatakan secara pribadi 2)Membandingkan hasil wawancara dengan isi suatu dokumen yang saling berkaitan 3)Mengadakan perbincangan dengan banyak pihak untuk mencapai pemahaman tentang suatu atau berbagai hal.

Proses analisis data dilakukan dalam penelitian ini adalah teknik analisis deskriptifkualitatif. Menurut Miles dan Huberman dalam (Sugiyono, 2011) meliputi pengumpulan data, reduksi data, penyajian data dan penarikan kesimpulan/verifikasi. Reduksi data yang berarti merangkum, memilih hal-hal yang pokok, memfokuskan pada hal-hal yang penting, dicari tema dan polanya dan membuang yang tidak perlu. Penyajian data dan coding dilaksanakan sebagai proses analisis untuk merakit data yang ditemukan di lapangan dan selanjutnya diikuti dengan interpretasi untuk memaknai hasil temuan tersebut. Penarikan kesimpulan merupakan langkah akhir berdasarkan data yang disajikan untuk memaknai permasalahan yang diteliti.

\section{HASIL PENELITIAN DAN \\ PEMBAHASAN}

Perencanaan Supervisi Akademik Sekolah Dasar Islam Terpadu Ash-Haabul Kahf Lubuk Alung

Perencanaan merupakan sesuatu yang harus dilakukan sebuah organisasi dalam 60 mencapai tujuannya. Hasil temuan supervisi akademik di Sekolah Islam Terpadu AshHaabul Kahfi sudah sesuai dengan standar perencanaan supervisi, seperti pelaksanaan rapat sekolah dalam menyusun program supervisi, penyusunan jadwal supervisi, dan sosialisai terkait instrumen yang akan digunakan dalam supervisi. Hasil temuan penelitian ini mendukung penelitian yang dilakukan oleh (Peninnah, 2012) bahwa 62\% guru memberikan tanggapan positif terhadap peranan kepala sekolah pada tahap perencanaan akademik di SMP Kabupaten Kitui Kenya, artinya kepala sekolah memiliki komitmen dalam memberikan pengarahan dan selalu berkomunikasi sebelum supervisi dilaksanakan.

Program perencanaan yang dilakukan oleh Sekolah Dasar Islam Terpadu Ash-Haabul Kahfi dalam pengelolaan supervisi akademik adalah dengan merujuk pada identifikasi masalah yang disampaikan guru pada saat rapat sekolah, keluhan siswa dan orang tua. Masalah yang teridentifikasi selanjutnya dianalisis oleh kepala sekolah sebagai bahan atau landasan dalam proses perencanaan supervisi akademik, penyusunan jadwal, dan pemahaman tujuan dari supervisi yang akan dilakukan. Tanggapan ustadzah H. Dra. Huriah selaku kepala sekolah di Sekolah Dasar Islam Terpadu Ash-Haabul Kahfi Lubuk Alung, mengatakan bahwa beliau bersama dengan guru dan karyawan telah membuat program perencanaan kegiatan supervisi pada awal tahun ajaran baru dan telah mensosialisasikannya pada forum rapat sekolah di setiap bulannya.

Penekanan pengelolaan supervisi akademik guru pada dasarnya berawal dari perencanaan, pelaksanaan, penilaian dalam proses pembelajaran. Artinya, supervisi akademik mampu menghadirkan pencapaian maksimal dari proses pembelajaran jika dilaksanakan dengan baik dan benar. Karena tujuan dari supervisi akademik tersebut adalah perbaikan pengajaran dan peningkatan 
kompetensi guru mulai dalam merencanakan yang dapat dilihat dari cara guru merancang silabus dan RPP. Melaksanakan pembelajaran dengan inovatif dan menyenangkan serta kemampuan guru dalam memberikan penilaian hasil belajar siswa. Sebagaimana penelitian (Mislaini Simanjuntak, 2013) menyatakan bahwa salah satu usaha untuk meningkatkan kualitas pembelajaran dan profesionalitas guru melalui pembinaan.

Guru sebagai objek yang akan disupervisi sudah mendapatkan sosialisasi terkait jadwal supervisi dan instrumen supervisi dua minggu sebelum pelaksanaan supervisi akademik. Guru juga diminta untuk mempersiapkan semua administrasi yang terkait dengan supervisi akademik, seperti: Program tahunan, Program semester, Silabus, KKM, RPP, Absen siswa dan penilaian.

Kepala sekolah menggunakan supervisi terpogram. Supervisi terprogram adalah kegiatan supervisi yang memiliki jadwal secara sistematis. Masing-masing guru mendapatkan jadwal kunjungan kelas minimal satu kali dalam satu tahun.

\section{Pelaksanaan Supervisi Akademik Sekolah Dasar Islam Terpadu Ash-Haabul Kahfi Lubuk Alung}

Supervisor haruslah mengetahui dan paham perihal teknik pelaksanaan supervisi akaemik. Berdasarkan hasil temuan Pelaksanaan yang dilakukan kepala sekolah dalam melaksanakan supervisi akademik adalah berupa kunjungan kelas secara langsung dan tidak langsung. Supervisi langsung bermaksud untuk melihat proses belajar mengajar yang dilaksanakan guru. Sebelumnya kepala sekolah meminta guru untuk menyiapkan segala admnistrasi guru untuk diperiksa dan dinilai sesuai dengan instrumen penilaian supervisi. Pelaksanaan supervisi tidak langsunng yang dilakukan kepala sekolah adalah dengan melihat kelengkapan administrasi guru saja tanpa melakukan kunjungan kelas, pemanggilan dan pembinaan guru. Hal ini sesuai dengan pendapat dari (Sagala, 2010) yang menyatakan bahwa ada beberapa teknik yang dapat digunakan oleh kepala sekolah dalam membantu guru meningkatkan situasi belajar mengajar, baik secara kelompok maupun secara perorangan ataupun dengan cara langsung bertatap muka dan cara tak langsung bertatap muka atau melalui media komunikasi.

Jadwal pelaksanaan dilaksanakan sesuai dengan kebutuhan dan kondisi guru. Maksudnya guru yang paling bermasalah adalah guru yang mendapat prioritas untuk dikunjungi dengan tujuan agar permasalahan bisa diatasi dengan cepat. Hasil wawancara dari ustadzah Irma Yuliani, S.Pd selaku guru kelas yang mengajar di kelas 5 Sekolah Dasar Islam Terpadu Ash-Haabul Kahfi Lubuk Alung pada tanggal 20 September 2019, mengatakan bahwa terkadang supervisi akademik tidak terlaksana sesuai jadwal yang telah di sosialisasikan. Hal ini karena banyaknya agenda kepala sekolah yang bersamaan dengan agenda dinas luar seperti rapat periodik, pertemuan di Dinas Pendidikan, pertemuan di UPW, tamu, pelatihan kepala sekolah, dan lainnya. Sehingga menyebabkan terjadinya "jadwal mundur" atau penundaan pelaksanaan supervisi akademik. Namun, kepala sekolah tidak mensosialisasikan jadwal terbaru kembali, sehingga membuat sebagian guru merasa pelaksanaan supervisi akademik menjadi "dadakan". Bahkan ada juga guru yang belum pernah mendapatkan kesempatan di supervisi karena terlupa dengan kesibukan kepala sekolah.

Hasil temuan juga menyatakan bahwa pelaksanaan supervisi akademik dimulai dari guru yang paling bermasalah. Hal ini bertujuan agar permasalahan yang dihadapi guru dapat diatasi dengan cepat. Sebagaimana hasil penelitian (Herly, 2014) menyatakan bahwa pelaksanaan supervisi dan instrumen supervisi yang bertujuan membina guru-guru yang memiliki kelemahan-kelemahan, serta tercipta 
suasana kerja yang baik setelah melakukan supervisi yang dilakukan oleh supervisor.

\section{Tindak Lanjut Supervisi Akademik Sekolah Dasar Islam Terpadu Ash-Haabul Kahfi}

Evaluasi adalah hal penting dalam proses pengambilan keputusan. Pemilihan informasi yang tepat, penugumpulan dan analisis informasi agar data yang didapat tepat sasaran. Kepala sekolah sebagai supervisor haruslah paham tentang unsur yang akan di evaluasi dari guru. Penilaian mencakup berbagai hal dari apa yang sudah diamati dari proses pembelajaran yang disupervisi. Hal ini sejalan dengan penelitian yang dilakukan oleh (OS, 2014) bahwa ada beberapa indikator yang diukur kepala sekolah untuk mencapai efektivitas penilaian, yakni (1) Bagaimana guru menguasai materi pelajaran (2) Bagaimana keterampilan mengajar guru (3) Bagaimana guru menggunakan sumber bahan ajar.

Evaluasi atau penilaian yang dilakukan kepala sekolah dalam supervisi akademik adalah setelah pelaksanaan supervisi berlangsung. Kepala sekolah memberikan penilaian sesuai instrumen supervisi berupa angka dan catatan kecil selama supervisi berlangsung. Dalam hal ini kepala sekolah hanya berfokus pada kelengkapan administrasi saja. Kepala sekolah tidak pernah memberitahukan perihal nilai dari hasil supervisi yang telah dilaksanakan kepada guru.

Di lapangan, kepala sekolah hanya memberikan tindak lanjut terkait administrasi guru. Jika guru lengkap administrasinya, maka guru tersebut dianggap tidak bermasalah. Namun, jika administrasi guru tidak lengkap, maka kepala sekolah akan menindak lanjuti dengan memberikan nasehat dan motivasi agar guru tersebut mau mengerjakan dan melengkapi administrasi, namun tidak memberikan batasan waktu untuk pengumpulannya.

Hasil wawancara dari ustadzah Fitri Sovia selaku guru yang mengajar di kelas 3 di Sekolah Dasar Islam Terpadu pada tanggal 23 62
September 2019, bahwa penilaian yang dilakukan kepala sekolah dalam pelaksanaan supervisi akadeimik di Sekolah Islam Terpadu Ash-Haabul Kahfi hanyalah berfokus pada administrassi saja. Dalam hal ini, terkesan kepala sekolah tidak melakukan proses tindak lanjut secara serius, sehingga tidak membawa perubahan lebih baik bagi guru ke depannya. Kepala sekolah sebagai supervisor tidak menjalankan tugas dan fungsinya sebagai supervisor yang baik. Dimana seorang supervisor hendaklah mengamati proses pembelajaran secara menyeluruh, seperti rancangan RPP yang sudah dibuat guru, cara guru mengelola siswa di dalam kelas, sumber media yang digunakan guru untuk mencapai tujuan pembelajaran, relevansi penilaian guru terhadap materi pelajaran, sikap guru selama menyajikan proses pembelajaran.

Setelah semua pengamatan tersebut dilaksanakan, maka kepala sekolah hendaknya melakukan pemanggilan guru secara individu untuk memberikan treatmen (perlakuan) sesuai dengan tingkatan perilaku guru. (D.Glickman et al., 2007) membagi tingkatan guru menjadi empat, yaitu (1) Guru Kuadran I adalah kategori guru kurang berkualitas dan perlakuan supervisinya adalah melalui supervisi langsung (2) Guru Kuadran II adalah guru yang tidak fokus dimana perlakuan yang harus diberikan melalui supervisi kolaboratif (3) Guru Kuadran III adalah guru kritis dimana perlakuan yang diberikan adalah supervisi kolaboratif dan (4) Guru kuadran IV adalah guru profesional dimana perlakuan supervisi yang diberikan adalah melalui supervisi tidak langsung.

Guru merasa kurang puas karena kepala sekolah tidak pernah memberikan pembinaan terkait administrasi yang mereka buat. Mereka tidak pernah tahu apakah yang mereka buat sudah benar atau belum. Selain itu kepala sekolah juga tidak pernah menindak lanjuti perihal proses pembelajaran yang dilaksanakan. Oleh karena itu guru lebih cenderung berdiskusi dengan rekan sejawat untuk memperoleh solusi 
dari setiap permasalahan yang mereka hadapi di kelas karena kepala sekolah hanya sibuk dengan urusan kantor.

Kondisi ini tidak sejalan dengan hasil penelitian (Setiyono, 2005) yang menyatakan bahwa agar supervisi mendapatkan hasil yang baik, hendaknya supervisor bersikap bersahabat, mendengarkan pembicaraan, berusaha meningkatkan partisipasi, ikut menyumbang teknik menganalisis permasalahan, memberi saran-saran, mencatat rencana, membuat ringkasan dan membuat penilaian.

\section{SIMPULAN DAN SARAN}

Berdasarkan hasil pembahasan dan analisis yang dilakukan peneliti, maka ditarik kesimpulan sebagai berikut : (1) Pada proses perencanaan kepala sekolah sudah melaksanakannya dengan baik dan terarah. Guru merasa dilibatkan untuk menentukan program dan waktu pelaksanaan supervisi akademik. Selain itu sosialisasi terkait instrumen supervisi pun sudah dijelaskan kepala sekolah melalui rapat guru. (2) Pada pelaksanaan supervisi akademik, kepala sekolah hanya berfokus pada pemeriksaan administrasi guru saja. Sehingga tujuan dari supervisi untuk meningkatkan kompetensi dan profesioanalitas guru dalam mengajar tidak tercapai. (3) Pada proses tindak lanjut supervisi akademik, kepala sekolah tidak melakukan penilaian dan tindak lanjut secara menyeluruh seperti administrasi guru, kemampuan guru dalam pengelolaan kelas, penguasaan materi pelajaran, sumber bahan ajar, media ajar, dan relevansi penilaian dengan materi ajar. Kepala sekolah hanya melakukan penilaian administrasi dan hanya menindaklanjuti guru yang tidak melengkapi administrasi.

Dari hasil uraian diatas, dapat disimpulkan bahwa pengelolaan supervisi akademik di Sekolah Dasar Islam Terpadu AshHaabul Kahfi Lubuk Alung belum baik, karena kepala sekolah kurang memahami makna dari supervisi akademik yang dilaksanakan.

Berdasarkan hasil pembahasan dan kesimpulan, maka saran peneliti sebagai berikut: (1) Kepala sekolah harus benar-benar mengerti dan memahami makna supervisi akademik yang dilaksanakan, mulai dari merencanakan, melaksanakan,evaluasi dan tindak lanjut sebagai bentuk usaha untuk meningkatkan guru yang berkompeten dan profesioanal di bidang pengajaran. Pemahaman yang diterima terkait supervisi akademik, hendaklah disosialisasikan kepada guru, agar guru merasa bahwa supervisi itu adalah kebutuhan, bukan takut untuk dinilai. (3) Pengawas sekolah, selaku pembina dari kepala sekolah mesti mengadakan pelatihan dan bimbingan kepada kepala sekolah, agar tujuan dari supervisi bisa dicapai secara maksimal.

\section{DAFTAR PUSTAKA}

Adisasmita, R. (2011). Pengelolaan Pendapatan dan Anggaran Daerah. Yogyakarta: Graha Ilmu.

D.Glickman, C., Gordow, S., \& Ross-Gordon, J. M. (2007). Supervision and Instructional Leadership. New York: Pearson Education,Inc.

Daryanto, \& Rachmawati, T. (2015). Supervisi Pembelajaran Inspeksi Meliputi: Cpntrolling, Correcting,Judging, Directing Demonstration (1st ed.). Yogyakarta: Gaya Media.

Follet, M. P. (2007). Manajemen. Jakarta: Indeks.

Handoko T. Hani. (2011). Manajemen Personalia dan Sumberdaya Manusia. Yogyakarta: BPFE.

Hasibuan., M. S. P. (2005). Manajemen Sumber Daya Manusia. Jakarta: PT Bumi Aksara.

Herly. (2014). "Upaya Kepala Sekolah Meningkatan Pelaksanaan Supervisi di 
Sekolah Dasar 015 Kempas." Jurnal Administrasi Pendidikan, 2(1), 312314.

Hersey, P., Blanchard, K. H., \& Johnson, D. E. (2008). Management of Organizational Behavior. Pearson Education,Inc.

Kristiawan, M., Yuniarsih, Y., \& Fitria, H. (2019). Supervisi Pendidikan [Educational Supervision]. Bandung: Alfabeta.

Mislaini Simanjuntak. (2013). Kemampuan Manajerial Kepala Sekolah dalam Pembinaan Kompetensi Profesional Guru pada SMK Negeri 1 Banda Aceh. Jurnal Pendidikan Serambi Ilmu, 15(2), 76-82.

Mulyasa, E. (2011). Manajemen dan Kepemimpinan Kepala Sekolah. PT. Bumi Aksara.

OS, A. (2014). "Instructional Improvement of Secondary School Teachers through Effective Academic Supervision by the Vice-Principals." Journal of Education and Human Development, 3(2).

Peninnah, N. (2012). "Role Of The Headteacher In Instructional Supervision As Perceived By Teachers In Secondary Schools In Kitui District,
Kitui CountyKenya”. A Research Project: The School Of Education Of Educational Administration Of Kenyatta University, $\mathrm{Na}$.

Rifma. (2016). Optimalisasi Pembinaan Kompetensi Pedagogik Guru. Jakarta: KENCANA.

Sagala, S. (2010). Supervisi Pembelajaran dalam Proses Pendidikan. PT. Remaja Rosda Karya.

Sahertian, P. A. (2010). Supervisi Pembelajaran dan Profesi Pendidikan. Bandung: Alfabeta.

Setiyono, I. (2005). "Supervisi Pendidikan Sekolah Dasar." Jurnal Pendidikan Dasar, 6(1), 1-8.

Snae, Y. D. I., Budiati, A. C., \& Kumalayanti, S. (2017). MODUL SUPERVISI AKADEMIK. Jakarta: Direktorat Jenderal Guru dan Tenaga Kependidikan.

Sugiyono. (2011). Metode Penelitian Pendidikan. Bandung: Alfabeta.

Supardi. (2014). Kinerja Guru [Teachers' Performance]. Jakarta: PT Raja Grafindo Persada. 